\title{
The Dutch experience: reciprocal influences between (socio-)political processes and casemix systems
} Anna van Poucke

\author{
Address: DBC-Onderhoud, Oudlaan 4, 3515 GA Utrecht, The Netherlands
}

Email: Anna van Poucke - a.van.poucke@dbconderhoud.nl

from 23rd Patient Classifications Systems International (PCSI) Working Conference

Venice, Italy. 7-10 November 2007

Published: 26 November 2007

BMC Health Services Research 2007, 7(SuppI I):AI doi:I0.II86/1472-6963-7-SI-AI

This abstract is available from: http://www.biomedcentral.com/I472-6963/7/SI/AI

(C) 2007 van Poucke; licensee BioMed Central Ltd.

\section{Introduction}

The Dutch DBC-system was developed and implemented between 2000 and 2005. When compared to other members of the 'classification family tree' it can be concluded that the system is not a logical step in the general line of development of classification systems. On a number of characteristics the Dutch system stands out from the other systems. One major differing characteristic being the fact that the system is not based on an internationally recognised classification system, but on 24 different systems of diagnosis classification, developed by different specialist medical associations. This results in 24 product structures that cannot be compared amongst each other. Another main difference with 'classical DRG-systems' is the episode of care rather than the encounter as a basis of the DBC-product. In the presentation we will investigate into the underlying political process that led to the creation of a deviant system. We will highlight some benefits of the system, but will also point out the fundamental changes that are needed to combine the benefits of the DBC with the benefits of DRG-systems. We will conclude with some assumptions on how the fundamental changes will reciprocally influence the socio-political relations in the Dutch health landscape.

\section{The development of the DBC-system: socio- political influences}

The Dutch 'healthcare landscape' consists, apart from governmental organisations, of a number of strongly organised national associations representing amongst others insurers, public and private health providers and medical associations. These parties are embedded in a 'processdesign' that is based on consensus decision making as opposed to 'enlightened despotism'. Due to the influences and counter-influences of the national associations and the culture of consensus decision making, the resulting DBC-system can be qualified as a 'negotiated product' rather than an 'expertise product'. On the basis of an analysis of stakeholders and their different interests some design-characteristics of the DBC-system can be explained. Interests of a majority of self-employed medical specialists, had a strong influence on the creation of 24 diagnosis classification systems. The strong position of public providers as opposed to the marginal position of private providers seems to account for the emphasis on classification rather than funding in the use of the DBCsystems. A map will be drawn representing positions, relations, influence-weights and outcomes of the process.

\section{Results and discussion}

Benefits of the DBFC-system and changes to be made: The DBC-system induced major culprits necessitating fundamental changes, but the system also provides advantages to the classical DRG-system. Detailed products give a high level transparency of diagnoses, processes and costs, providing feedback to hospitals to redesign their processes and develop efficiency and quality interventions. Strong involvement of the medical profession in the design of the system increased insight into effects of medical decisions on costs of the system. Information on the whole episode of care provides an incentive to increase efficiency by substitution of inpatient care by day- and outpatient care. 
Despite the benefits, the pitfalls posed by the system will lead to fundamental changes in the system, combining strong points of actual DRG-systems, with benefits of the DBC system.

\section{Influence of system changes on the Dutch healthcare system}

Fundamental changes to the DDB-changes have been proposed but not yet implemented. Still we will attempt to draw out some tentative assumptions about how a changed system may influence positions and relations within the Dutch healthcare landscape.

Publish with Bio Med Central and every scientist can read your work free of charge

"BioMed Central will be the most significant development for disseminating the results of biomedical research in our lifetime. " Sir Paul Nurse, Cancer Research UK

Your research papers will be:

- available free of charge to the entire biomedical community

- peer reviewed and published immediately upon acceptance

- cited in PubMed and archived on PubMed Central

- yours - you keep the copyright

Submit your manuscript here:

http://www.biomedcentral.com/info/publishing_adv.asp 